\title{
A imagem que cheira mal: as charges de Sampaulo e de Santiago sobre o caso Borregaard/Riocell durante a década de 1970
}

\section{Dante Guimaraens Guazzelli ${ }^{1}$}

Em 17 de março de 1972, começa a funcionar em Guaíba, às margens do Lago Guaíba, a fábrica da empresa de celulose de origem norueguesa Borregaard. A instalação da empresa foi fruto de um esforço da ditadura civil-militar brasileira que, para isso, passou por cima de procedimentos padróes, como a necessidade de alvará da Secretaria Estadual de Saúde e de pareceres favoráveis à sua instalação. ${ }^{2}$ Logo que se iniciam os trabalhos da fábrica, a população porto-alegrense é afetada pelo mau cheiro: isso provoca grande transtornos na saúde dos habitantes, resultando em problemas como tonturas, irritação das mucosas, náuseas e vômitos, além de grande revolta por parte da população. ${ }^{3}$

Partindo desse acontecimento, a sociedade porto-alegrense e gaúcha começou a tomar consciência das questóes ecológicas e da necessidade de diminuição do impacto ambiental, ajudando a dar mais repercussão a demandas de grupos ecologistas, como a Associação Gaúcha de Proteção Ambiental (Agapan). ${ }^{4}$

1 Mestre em História/UFRGS

2 LUSTOSA, Caio; BENITES, Eva. Luta ambiental e cidadania: da Borregaard e outros episódios. Porto Alegre: Editora Da Casa/Palmarinca, 2008, p. 11.

3 Idem, ibidem.

4 DREYER, Lilian. Borregaard: um marco da luta ambiental no Rio Grande do Sul. p. 2. Disponível em http://poavive.files.wordpress.com/2011/04/borregaard-liliam-dreyer.pdf. 
Procurarei, aqui, analisar quatro charges publicadas no jornal Folha $d a$ Tarde durante a década de 1970 em Porto Alegre e que tratam diretamente do "caso Borregaard", de autoria de Sampaulo e Santiago. ${ }^{5}$ As charges foram pesquisadas no acervo privado da sobrinha do cartunista Sampaulo, Maria Lúcia Sampaio, e no acervo privado do cartunista Santiago. ${ }^{6}$

Como afirma Rodrigo Patto Sá Motta, as charges e caricaturas constituem documentos muito ricos para o conhecimento histórico, já que podem "funcionar, simultaneamente, como crônica e interpretação, pois não é fácil separar o ato de informar e a ação de interpretar os eventos políticos" .

Após essa grande campanha popular, o governador Euclides Triches autorizou o fechamento da fábrica em 9 de dezembro de 1973, o que durou somente três meses, sendo esta reaberta em 14 de março de $1974 .{ }^{8}$

Sobre essa situação, temos a charge de Sampaulo (Figura 1). Infelizmente, não existe no material consultado a referência à data de publicação. Porém, partindo das informaçôes da charge, incluindo o estilo de desenho que o artista apresenta, podemos dizer que ela é do período da abertura da fábrica.

O que vemos na Figura 1 são as silhuetas da cidade de Porto Alegre e da fábrica da Borregaard, separadas pelo Lago Guaíba. O que Sampaulo frisa é o absurdo da situação: em vez de a fábrica pedir para ficar ou se modificar, é a cidade de Porto Alegre que tem que alterar a situação. O que está latente aqui é o poder descomunal que a fábrica tem: dessa forma, o artista está mostrando, de forma indireta, o absurdo do projeto do governo brasileiro,

5 Sampaulo (pseudônimo de Paulo Sampaio) nasceu em Uruguaiana, Rio Grande do Sul, em 1939, e atuou entre 1955 e 1999, até sua morte, trabalhando nos jornais O Clarim, A Hora, Diário de Noticias, Folha da Tarde, Folha Esportiva e Correio do Povo. Santiago (pseudônimo de Neltair Rebés Abreu) nasceu em Santiago, Rio Grande do Sul, em 1950, e começou a trabalhar no início da década de 1970, atuando nos jornais Folha da Manhã, Folha da Tarde, Correio do Povo, Coojornal, Pasquim, O Estado de São Paulo, entre outros. Os dois artistas são reconhecidos internacionalmente, tendo conquistado diversos prêmios em salóes de desenho de humor no Brasil e no mundo e publicado diversos livros. Para maiores informaçóes sobre os cartunistas, visite os sites: http://www.caminhosdosantiago.com.br/ e http://sampaulocartunista.blogspot.com.brl.

6 Agradeço à família de Sampaulo e à de Santiago por terem aberto seus acervos e disponibilizado o material em questáo.

7 MOTTA, Rodrigo Patto Sá. Jango e o Golpe de 1964 na caricatura. Rio de Janeiro: Jorge Zahar Editor, 2006, p. 23.

8 LUSTOSA; BENITES, op. cit., p. 13. 
já que faz com que uma fábrica tenha mais força do que a população de uma grande cidade.

Após toda a repercussão que a empresa atraiu, em junho de 1974, a direção da fábrica passa para o ex-comandante do III Exército, General Breno Borges Fortes, indicado pelo governador Sinval Guazzelli. Em julho de 1975, os investidores noruegueses deixam a fábrica, passando o controle acionário para o Grupo Sul Brasileiro/Montepio da Família Militar, modificando-se o nome desta para Riocell. Posteriormente, em 1978, ela é estatizada e, em 1982, privatizada novamente. ${ }^{9}$

Essas modificaçóes, que visavam a mudar a imagem da fábrica, foram registradas/comentadas pelos chargistas, o que é representado na Figura 2. O artista frisa aqui que, apesar de o nome ter sido modificado, o que existia do outro lado do Guaíba era a "velha", feia e malcheirosa Borregaard. É interessante notar a ênfase dada por Santiago ao odor que a "senhora" produz.

Na Figura 3, Santiago mostra, assim como Sampaulo na Figura 1, o absurdo da situação, em que a fábrica é mais importante do que a cidade. Ao mesmo tempo, o chargista novamente frisa que a fábrica, com novo nome, é a "popular Borregaard": isso é um indício da repercussáo que o nome tomou no imaginário do porto-alegrense, virando sinônimo de mau cheiro.

Finalmente, temos a charge de Sampaulo (Figura 4), que aparentemente data do final da década de 1970. Nela, vemos retratada a estaçáo espacial estadunidense Skylab, que foi lançada ao espaço em maio de 1973 e desativada no final dessa década. ${ }^{10}$ Essa estação gerou grande repercussão, pois não havia controle de sua entrada na atmosfera no que se refere ao momento e à localização do ocorrido, o que gerou grande impacto na imprensa até julho de 1979, quando ela aterrissou no Oceano Pacífico. No desenho, vemos a Skylab caindo e a populaçáo de Porto Alegre torcendo para que caia na fábrica da Borregaard. Assim, as pessoas, literalmente, apelam aos céus que acabem com o transtorno que era essa empresa.

9 Idem, p. 17.

10 Sobre esse episódio, ver o artigo sobre a missão Skylab no sítio da Agência Espacial Norte-Americana, a NASA: http://www.nasa.gov/missions/shuttle/f skylab1.html. 


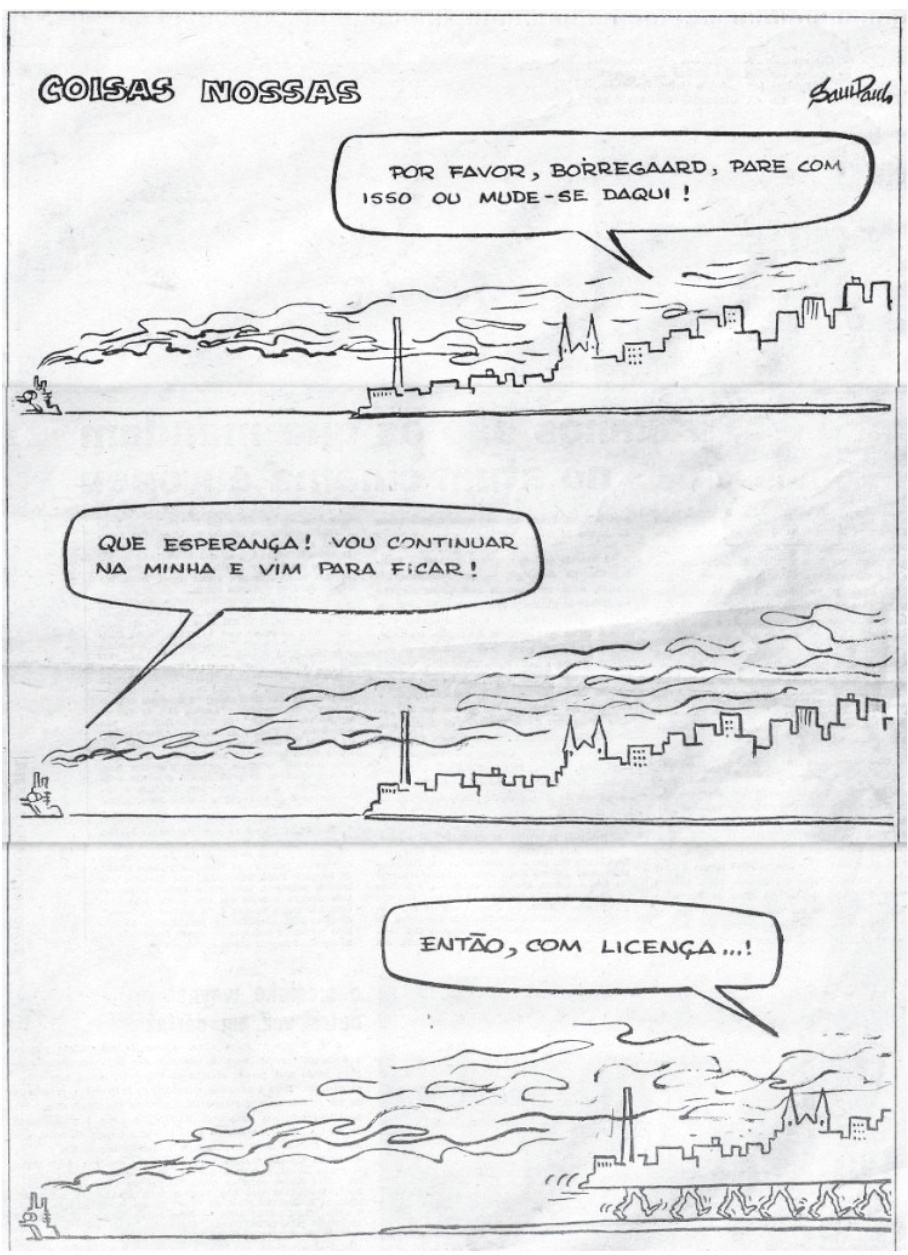

Fig. 1. Charge Sampaulo - Folha da Tarde 


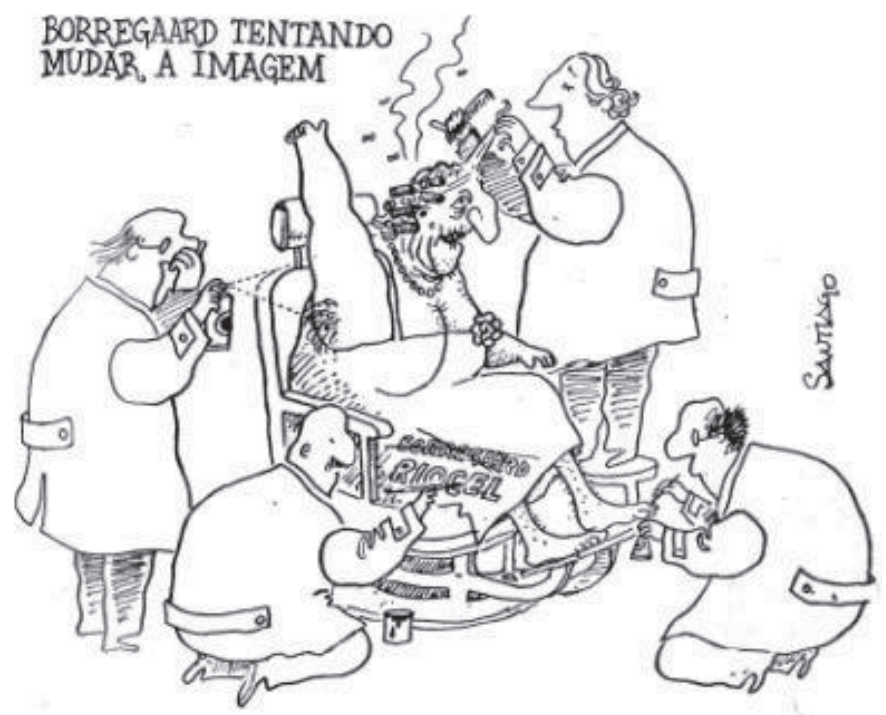

Fig. 2. Charge Santiago - Folha da Tarde / Julho de 1976

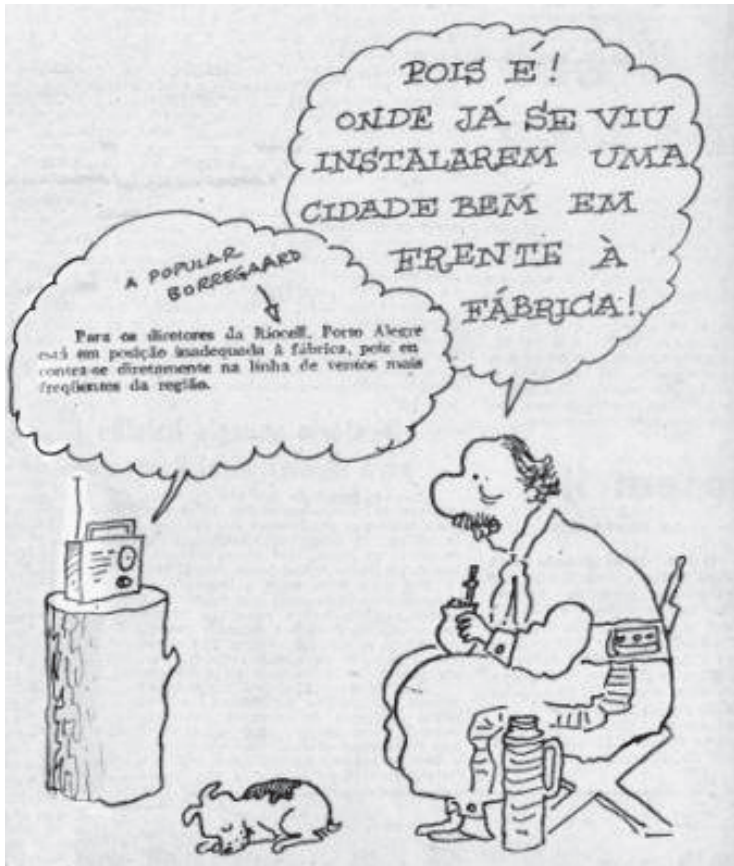

Fig. 3. Charge Santiago - Folha da Tarde / Setembro de 1976 

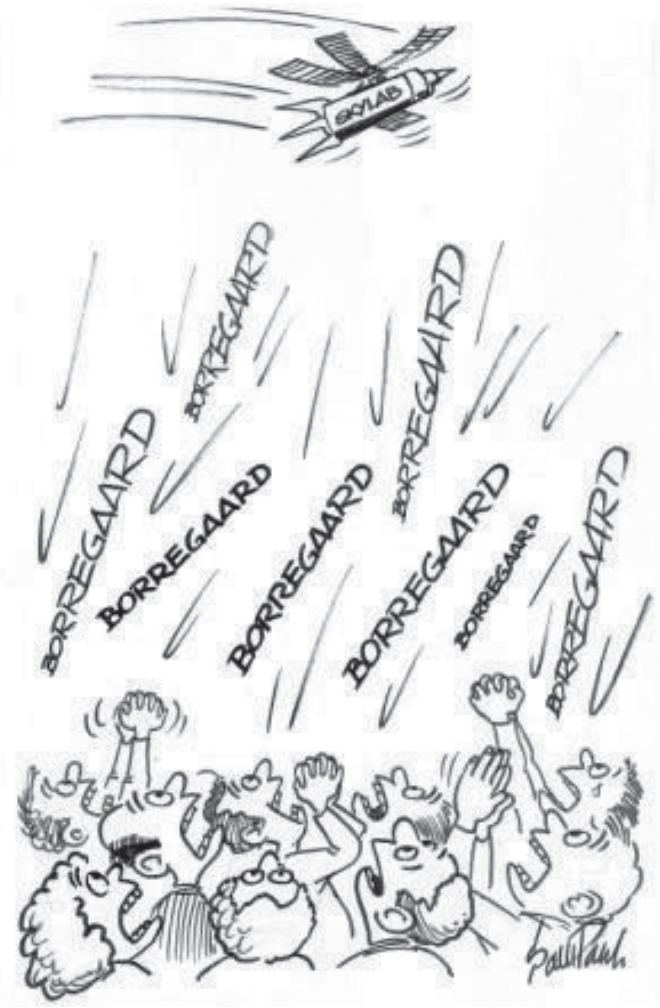

Fig. 3. Charge Sampaulo - Folha da Tarde

\section{Referências}

LUSTOSA, Caio; BENITES, Eva. Luta ambiental e cidadania: da Borregaard e outros episódios. Porto Alegre: Editora Da Casa/Palmarinca, 2008.

DREYER, Lilian. Borregaard: um marco da luta ambiental no Rio Grande do Sul. Disponível em http://poavive.files.wordpress.com/2011/04/borregaard-liliam-dreyer.pdf

MOTTA, Rodrigo Patto Sá. Jango e o Golpe de 1964 na caricatura. Rio de Janeiro: Jorge Zahar Editor, 2006.

SOARES, Vânia Fonseca. A Abertura Politica e os Movimentos Sociais em Porto Alegre (1979-85). Dissertação de Mestrado em História. UFRGS, Porto Alegre, 2002. 
Resumo: Este texto analisa charges dos chargistas Sampaulo e Santiago, produzidas durante a década de 1970 que tratam do caso Borregaard/Riocell. Em 1972, a fábrica de celulose Borregaard começa a funcionar em Guaíba/RS, trazendo muitos transtornos à população de Porto Alegre. As charges falam sobre o impacto que a fábrica trouxe e são indícios da mobilização da população.

Palavras-chave: charge, Caso Borregaard, ecologismo.

The image that stinks: the cartoons of Sampaulo and Santiago about the affair Borregaard / Riocell during the 1970s

Abstract: This paper analyzes cartoons produced during the 1970s and dealing with the case Borregaard / Riocell. In 1972, Borregaard pulp mill starts working in Guaíba / RS, bringing many disorders the population of Porto Alegre. The cartoons talk about the impact that the factory trousse and are evidence of mobilization of the population.

Keywords: cartoon, Affair Borregaard, environmentalism.

Recebido em: 02/08/2012

Aprovado em: 30/08/2012 